Proceedings of the 34th Meeting of the Association of Embryo Transfer in Europe (AETE); Nantes, France, September 7th and 8th, 2018.

\title{
Preservation of female fertility in humans and animal species
}

\author{
Helen Mary Picton ${ }^{1}$ \\ Reproduction and Early Development Research Group, Discovery and Translational Science Department, Leeds Institute Of \\ Cardiovascular and Metabolic Medicine, School of Medicine, University of Leeds, UK.
}

\begin{abstract}
A detailed understanding of the cryobiology of gametes and complex tissues has led to the development of methods that facilitate the successful low temperature banking of isolated mature human oocytes, or immature oocytes in situ within fragments of human ovarian cortex. Although many outstanding research challenges remain to be addressed, the successful development of new treatments to preserve female fertility for a range of clinical indications has largely been underpinned by the conduct of extensive, fundamental research on oocytes and ovarian tissues from a number of laboratory and commercially important farm species. Indeed, the most recent evidence from large animals suggests that it is also possible to cryopreserve intact whole ovaries along with their supporting vasculature for later autotransplantation and restoration of natural fertility. This review will explore how the methods developed to preserve human oocytes and ovarian tissues can now be used strategically to support the development of conservation strategies aimed at safeguarding the genetic diversity of commercially important domestic animals and also of preserving the female germplasm for wild animals and endangered species.
\end{abstract}

Key words: cryopreservation, fertility preservation, oocyte, ovary.

\section{Introduction}

In the last few decades, advances in cryobiology have been combined with the development of new assisted reproduction technologies (ARTs) and used as a means to cryopreserve the structural integrity and biological function of key reproductive cells. Translation of these research advances has resulted in the development of the capacity to cryopreserve and long-term store isolated gametes, embryos, complex gonadal tissues and even whole reproductive organs in humans and laboratory species as well as commercially important farm animal breeds and a limited number of exotic or endangered species. Indeed, the issue of fertility preservation is particularly relevant in animals as over the last two decades, some 300 of 6000 farm animal breeds have become extinct and a further 1350 domestic breeds are being threatened with extinction as a result of aggressive animal breeding strategies using limited genetic stocks of animals of high merit for a range of economically valuable traits (Taberlet et al., 2008).

The standard method of fertility preservation in males whether humans or animals is the cryopreservation and storage of sperm (for review see Ehmcke and Schlatt, 2008). Similarly, since the first successful cryopreservation of embryos in laboratory species in the early 1970s (Whittingham et al., 1972) thousands of animal and human offspring have been born following embryo cryopreservation. With regard to oocytes, the recent development of improved methods and devices for the vitrification of isolated cells has increased the success rates of metaphase II (MII), oocyte preservation in humans (Rienzi et al., 2017). This technological advance has only had limited application to the oocyte preservation in animals due to a general lack of basic understanding of oocyte biology in different target species (Comizzoli, 2017). While sperm, oocytes and embryo preservation using ART are clearly effective, recent research focus has shifted to the preservation of gametes in situ either within fragments of ovarian and testicular tissue or following whole organ cryopreservation. Indeed, the banking of gonadal tissue is particularly valuable as a means of preserving fertility as in the case of the ovary the banked tissue may contain thousands of the earliest staged primordial follicles and oocytes. In contrast testicular tissue cryopreservation facilitates the banking of spermatogonial stem cells that can subsequently can be harvested and used to repopulate the testis and restart spermatogenesis (Picton et al., 2015). Although no standardized protocols exist for fertility preservation in any species, the preservation of gonadal tissues offers near unlimited potential for fertility preservation and restoration in humans as well as domestic and wild animal species. This review aims to provide an overview of the recent advances in human oocyte and ovarian tissue banking and how these clinical reproductive technologies can be used to support fertility conservation strategies in animals.

\section{Cryobiology and fertility preservation}

Cryopreservation is a multi-step procedure that requires that cells tolerate exposure to: molar concentrations of penetrating and non-penetrating cryoprotective agents (CPAs); cooling to subzero temperatures; and either removal or conversion of the greater majority of liquid water within the cells into a solid state. The reverse occurs during thawing or warming. Any of these elements can inflict damage on the cells to be preserved although the level and nature of the damage is dependent on the cryobiological properties of each individual cell type. With regards to the cryopreservation of complex tissues containing

${ }^{1}$ Corresponding author: H.M.Picton@leeds.ac.uk

Received: June 25, 2018

Accepted: July 6, 2018 
multiple cell types, such as the ovary, the success of cryopreservation is dependent on the need to balance the freezing optima for a range of different cell types which are influenced by cell number and size and, in the case of oocytes, maturational status, as well as the requirement to preserve the structural integrity of the tissue. Furthermore, the nature of the cryopreservation methodology, whether slow freezing or vitrification, the cooling and warming rates and the containment vessel used for tissue preservation and storage will all influence the efficacy of the preservation method and hence impact on the subsequent viability of the preserved tissue. Finally, the unique biological properties of oocytes challenge our potential to freezestore these important cells. Mammalian oocytes are very large cells of approximately $120 \mu \mathrm{m}$ diameter with a small surface area to volume ratio and high lipid and water content. The latter confers a high sensitivity to chilling injury and intracellular ice formation. In MII oocytes these parameters are further confounded by the presence of a fragile cytoskeleton that is resistant to the volumetric excursions commonly associated with equilibrium freezing and a highly temperature sensitive meiotic spindle apparatus (Saragusty and Arav, 2011). These time-dependent sensitivities to chilling to $0^{\circ} \mathrm{C}$ are evident in MII oocytes from a range of species including mouse (Pickering and Johnson, 1987) rhesus monkey (Songsasen et al., 2002) and human (Pickering et al., 1990; Zenzes et al., 2001). Indeed, cooling oocytes to room temperature for even as little as 10 minutes can cause irreversible damage to the meiotic spindle. Furthermore, chilling oocytes to $0^{\circ} \mathrm{C}$ in the presence of a CPA appears to exacerbate these abnormalities (Mullen et al., 2004).

Despite these difficulties, significant advances have been made in our ability to cryopreserve MII oocytes in a range of species. The most convincing data on the efficacy of MII oocyte preservation is undoubtedly derived from human ART. Initial attempts to slow freezing human MII oocytes (Picton and Chambers, 2009) met with only limited success as evidenced by the key statistic of live birth rates per oocyte thawed (Oktay et al., 2006). Since then the efficacy of MII oocyte cryopreservation has increased dramatically with live birth rates following human MII oocyte vitrification by the best IVF clinics now being equivalent to those achieved during embryo freezing (Glujovsky et al., 2014; Rienzi et al., 2017). The improved efficiency of human MII preservation can be attributed to the development of optimized vitrification protocols that minimize the cells exposure to the cytotoxic impact of high concentrations of usually two or more CPAs including penetrating CPAs such as ethylene glycol and propanediol and non-penetrating CPAs such as sucrose or trehalose. Oocyte cooling rates during vitrification have also been maximized by the commercial development of specialized vitrification devices for use in ART that support the preservation of individual oocytes or small groups of cells within minimal volumes of cryopreservation reagents. As a result of these advances MII oocyte vitrification is no longer considered an experimental technique in human
ART (Rienzi et al., 2017) and the approach is regularly used to preserve oocytes for young women who are undergoing infertility treatment, teenage girls or young women who need to safeguard their future fertility before exposure to the ablative cancer treatments, or more controversially, young women who wish to delay childbearing and elect to safeguard their future fertility by oocyte banking (Cobo et al., 2016). Regardless of species, it is clear that the success of oocyte cryopreservation is dependent on oocyte quality, a key parameter that is profoundly and negatively influenced by advancing maternal age (Goldman et al., 2017).

While significant improvements have been made in human MII oocyte vitrification these methods have had only a limited impact on oocyte banking in animals over and above the laboratory and livestock species that are used as models for the development and testing of the human ART protocols (Wildt et al., 2010). Never-the-less encouraging results for MII vitrification have been obtained in some domestic species such as the cat (Fernandez-Gonzalez and Jewgenow, 2017) as well as some exotic species including for example the Tasmanian devil (Czarny and Roger, 2010) and Mexican gray wolf (Boutelle et al., 2011). While commonalities in the biophysical traits associated with cell freezing between taxonomically-related species may be useful to inform protocol development and support improved post-thaw viability across species, in general the similarities between taxa tend to be overshadowed by the magnitude of species specific differences in the ability of their oocytes to tolerate osmotic and toxic effects of CPA exposure and chilling injury (Woods et al., 2004). For example, felid oocytes appear far more tolerant to osmotic changes and cold temperatures than oocytes from bovids, cervids or equids that appear to be more sensitive to cold shock (Comizzoli et al., 2010, 2012). Overall the ability of MII oocytes to survive the freezing and thawing, or cooling and warming processes is highly variable and difficult to predict across species (for review see Comizzoli et al., 2012). Thus despite the advances that have been made with MII oocyte cryopreservation in humans, fundamental cryobiological investigations and further optimization of oocyte cryopreservation protocols combined with comparative studies across species are needed before MII oocytes cryopreservation can be used efficiently to preserve the fertility of wild or endangered animals, especially where the numbers of oocytes available for preservation are limited.

Some of the difficulties associated with the cryopreservation of MII oocytes may potentially be overcome by the preservation of fully grown, but nuclear immature, germinal vesicle $(\mathrm{GV})$ staged oocytes. However, this option has proved inconsistent and like the MII oocyte preservation detailed earlier, success rates appear to be influenced by species. In addition to rodent and ruminants, successful GV oocyte vitrification has recently been reported in equids (OrtizEscribano et al., 2018) and domestic cats. The evidence suggests that GV oocytes appear to be more cryoresistant than their MII counterparts (Comizzoli et al., 2008). Regardless of species, GV oocytes 
cryopreservation requires the freeze-storage of both the gamete and its supporting compliment of cumulus granulosa cells. The success of GV oocyte cryopreservation is critically dependent on the postthaw/warming maintenance of the functional integrity of the heterologous gap junctional contacts connecting the cumulus cells to the oocyte. This network of cumulus cells supply the oocyte with vital nutrients and signaling molecules that are essential to drive the cytoplasmic and nuclear maturation of the oocyte to the MII stage. Furthermore, cumulus cells have a discretely different cryopreservation optima compared to oocytes. The loss of gap junctional contacts between the cumulus cell compartment and the GV oocyte is a common casualty of the cryopreservation process such that both the capacity of the oocyte to under go in vitro maturation and its subsequent fertile potential and developmental competence are severely compromised. Finally, GV oocyte preservation must be supported by the provision of robust culture environments that support oocyte maturation in vitro. Insight into the discrete, speciesspecific differences in the composition of the culture environment required to drive oocyte maturation will be needed to maximize oocyte quality after cryopreservation.

Regardless of their stage of nuclear maturity secondary oocytes can be harvested in humans and other mammalian species by ultrasound-guided laparoscopy or by laparotomy. Controlled ovarian stimulation with exogenous hormones is frequently used to increase the number of appropriately staged antral follicles at the time of oocyte aspiration. Alternatively, secondary oocytes can be harvested by needle aspiration of antral follicles at any stage of the reproductive cycle following ovariectomy, or as a byproduct of surgical procedures or following the natural mortality of an animal.

\section{Ovarian tissue preservation}

Many of the biophysical challenges associated with preserving secondary oocytes can be avoided by the banking of immature primordial oocytes through ovarian tissue cryopreservation. Indeed, the biological characteristics of primordial oocytes are well suited to preservation since primordial oocytes are relatively undifferentiated and, in the case of humans, are 3-4 fold smaller in diameter than their secondary oocyte counterparts. Importantly, primordial oocytes represent the building blocks of female reproduction and, depending on age, the mammalian ovarian cortex is endowed with thousands to millions of primordial oocytes enclosed within primordial follicles (Picton, 2001). The quantity and quality of the primordial follicles within this ovarian reserve ultimately defines the reproductive longevity and fertile potential of an individual. While our understanding of the mechanisms that regulate the activation of primordial follicle growth and hence depletion of the ovarian reserve is limited, especially in wild animals and there is considerable variability between species, ultimately the ovarian reserve represents the major germplasm resource that can be consistently and safely banked by wildlife reproductive biologists, veterinarians and clinicians alike as a means of safeguarding future fertility and maintaining genetic diversity.

Strategies for ovarian tissue cryopreservation are predominantly centered around the preservation of primordial follicles in situ either within fragments of ovarian cortex or by banking the whole ovary. It is possible to freeze-store isolated primordial oocytes but in the absence of supporting ovarian stromal cells these presumptive gametes have only limited viability post thaw/warming. The efficacy of ovarian cryopreservation is dependent on: optimization of the cryopreservation protocol for the species of interest; the individual's age at the time of tissue harvest and storage; the requirement to successfully preserve both the structural integrity and biological complexity of the tissue. Ovarian cortical tissue is comprised of functionally diverse cell types including immature GV oocytes, follicular somatic cells, stromal cells, blood vessels and the ovarian surface epithelium (Picton et al., 2000; Picton, 2001). All of these cell types have different cryopreservation optima and all play different but important functional roles in supporting the activation and completion of follicle and oocyte growth and as well as the maintenance of the ovarian reserve, whether in vivo or in vitro. Finally, strategies designed to successfully preserve the integrity and fertile potential of ovarian tissues and, conversely, to limit cryo-damage need to be developed in parallel with the methods to use the tissue to restore fertility following banking. Despite these challenges ovarian tissue cryopreservation have been optimized and used successfully for a range of species including mice, rats, rabbits, cats, dogs, sheep, goats, cows, pigs, horses, camels, wallabies, wombats, dasyurids, elephants, monkeys and humans (for review see Devi and Goel, 2016).

The majority of methods used to cryopreserve ovarian tissue are based on the original validated slow freezing protocols developed for the successful cryopreservation of human ovarian cortex as published by Newton et al. (1996) and the associated publications and live births recorded in sheep by Gosden et al. (1994) and Baird et al. (1999). In general, ovarian cortex is harvested following ovary removal or ovarian biopsy and thin fragments of cortex are equilibrated in CPA before undergoing controlled rate cooling with manual ice seeding before the temperatures are brought down to $-196^{\circ} \mathrm{C}$ and the tissue is stored at liquid nitrogen temperatures. There is now a substantial clinical evidence base to substantiate these early successes. Several thousand girls and young women worldwide have safeguarded their future fertility using ovarian tissue preservation methods. The most common indication for ovarian tissue banking is the need to preserve the future fertility of girls and women: who are at risk of premature ovarian failure (POF) following exposure to the ovotoxic impact of chemotherapy agents for the treatment of cancer (Gellert et al., 2018; Oktay et al., 2018) or other haematological pathologies such as sickle cell anemia (Demeestere et al., 2015) or beta thalassemia (Matthews et al., 2018); or who carry a high risk of POF for genetic conditions such as Turners 
syndrome (Oktay et al., 2016); or who will suffer ovarian tissue damage and loss following abdominal trauma.

The potential of the stored ovarian tissue to support fertility restoration when the individual wishes to start her family is demonstrated by the delivery of more than 130 healthy babies world wide after autotransplantation of the frozen-thawed tissue and the restoration of endocrine and ovarian function (Pacheco and Oktay, 2017) with more ongoing pregnancies being recorded. Although the overall efficiency of fertility restoration following ovarian tissue preservation and transplantation is unknown, recent evidence from defined cohorts of patients suggests a $\sim 30 \%$ live birth rate after autotransplantation of slow frozen-thawed ovarian cortex, (Jadoul et al., 2017; Keden et al., 2018). When fertility preservation strategies require the removal of the whole ovary and it is age appropriate to do so, ovarian cortex harvest and cryopreservation can be most effectively combined with methods for in vitro maturation and vitrification of MII oocytes to maximize the likelihood of a future successful pregnancy outcome for the patient. Although significant progress has been made in the development and use of ovarian tissue cryopreservation as a means to safeguard the future fertility of girls and young women at risk of POF, further optimization of the cryopreservation and transplantation protocols are likely to be beneficial as the longevity of ovarian autograft function following transplant remains unclear. The latter is likely to be determined by patient age at tissue harvest and by the degree of follicle loss that results from ischaemia and reperfusion injury following ovarian tissue transplantation. Importantly, further research is also needed to define and mitigate against any potential risk of reseeding cancer cells through the transplanted ovarian tissues (Dolmans and Masciangelo, 2018).

While the majority of successful live births have occurred following the slow freezing and autotransplantation of human ovarian tissues, recent evidence from a number of species, including women, suggests that it may also possible to preserve ovarian tissue by vitrification. Histological evaluations and assessment of the viability of oocytes grown in vitro from vitrified ovarian tissues have been published for a range of species including, for example, mouse (Tokieda et al., 2002; Migishima et al., 2003), sheep (Bordes et al., 2005) cow (Kagawa et al., 2009); goat (Santos et al., 2007, Carvalho et al., 2013); camel (Madboly et al., 2017) dog (Ishijima et al., 2006), nonhuman primate (Santana et al., 2012) and human (Suzuki et al., 2015). Collectively these results suggest that it is possible to maintain tissue integrity and oocyte health following super cooling and warming. However, other studies are more skeptical about the suitability of vitrification for ovarian cryopreservation and have recorded increased necrosis in vitrified ovarian tissues (Rahimi et al., 2004; Gandolfi et al., 2006). Overall, at the time of writing it appears that the outcome of ovarian tissue vitrification is far more variable than slow freezing methods and considerable further research effort is needed to optimize and validate vitrification protocols before this approach can be considered a reliable method for the preservation for complex ovarian tissues. Furthermore, the risk of freeze fracture of vitrified samples during long-term tissue storage and compatibility/ potential risk of de-vitrification of samples during tissue bank audits and/or transportation remains to be proven.

An alternative approach than can be used to maximize the preserved ovarian reserve whilst minimizing the potential for ischemic follicle loss following autografting is to cryopreserve and retransplant the whole ovary. This fertility preservation strategy involves the cryopreservation of not only the intact, whole ovary but also its supporting blood vessels (Martinez-Madrid et al., 2004; Baudot et al., 2007). Evidence to support the concept of the slow freezing and transplantation of whole ovaries and their supporting vasculature has been provided in sheep with the total restoration of natural fertility in all of the treated animals with $64 \%$ live birth rate following whole organ preservation and transplantation (Onions et al., 2009, 2013; Campbell et al., 2014).

\section{Lessons from human ART and tissue cryopreservation}

The development of strategies for human fertility preservation are informing the development of an equivalent agenda in animals. Valuable lessons can be learned from clinical ARTs and human fertility preservation programmes that can be applied to domestic livestock and also be used for the conservation of wild or endangered animals by the cryopreservation of sperm, oocytes and embryos and the preservation of intact gonadal tissues (Paulson and Comizzoli, 2018). Examples of exactly how the potential of bio banks and ARTs such as artificial insemination with cryopreserved sperm have been used successfully to save endangered animals are provided by giant pandas (Huang et al., 2012), domestic and wild carnivores (Comizzoli et al., 2009; Comizzoli and Wildt, 2012) and the black footed ferret (Howard and Wildt, 2009). In contrast to the successful use of sperm freezing, the recent progress made with human oocyte cryopreservation by vitrification has been far more difficult to translate to conservation programmes in animals due to a general lack of basic understanding of the complexity of mature oocyte biology and their cryo-sensitivity in different, target species (Comizzoli, 2017). Further collaborative research effort and cross species comparisons are clearly needed.

The practice of ovarian tissue preservation is highly relevant to the maintenance of the genetic diversity in domestic animals including bovine, ovine, caprine, swine and equine species as well as in wild animals. Indeed, the development of ovarian tissue cryopreservation and fertility restoration strategies in humans have been underpinned by animal models of ovarian freezing. For example, the original proof of principle studies used to establish CPA toxicity and penetrability into ovarian tissues and to determine if the histology and function of these tissues could be retained 
following slow freezing were conducted in mice (Harp et al., 1994) and marmosets (Candy et al., 1995) as well as humans (Newton et al., 1998). The efficacy of ovarian tissue preservation methods have been evaluated by histological analysis of frozen-thawed tissue and by assessment of follicle and oocyte morphology post thaw/warming in animal tissues, e.g. in cattle (Gandolfi et al., 2006) and sheep (Chambers et $a l ., 2010$ ) or after short term culture and staining for cell viability and/or apoptotic markers (Chambers et al., 2010). Furthermore, while sheep models of ovarian tissue cryopreservation and autografting provided the first definitive proof that cryopreserved ovarian tissue could be used to restore natural fertility with the production of live young in large animals (Gosden et al., 1994), live births has previously been reported in laboratory species including mouse (Parrot, 1960), rat (Wang et al., 2002) and rabbit (Almodin et al., 2004). Similarly, as detailed above the concept of the slow freezing and transplantation of whole ovaries and the supporting ovarian vasculature with the complete restoration of natural fertility has been demonstrated in sheep (Onions et al., 2009, 2013; Campbell et al., 2014). Other comparisons of the efficacy of whole ovary preservation by slow freezing $v s$. vitrification methods are ongoing across a range of species including mice, goat and cow in the anticipation that these experimental findings can in the future be translated for human use. Finally, xenografting was originally established as model to test the viability (Oktay et al., 1998), quality, integrity (Kim et al., 2005) and safety of the ovarian tissue transplantation following the preservation of tissue for cancer patients (Kim et al., 2001).

While ovarian tissue preservation can clearly be used to preserve and exploit the germplasm of domestic animals of high genetic merit, this technology is also particularly relevant to the preservation and longterm storage of the germplasm of rare or endangered species and/or indigenous native animal breeds where the creation of genetic resource banks is urgently required to maintain future genetic diversity. Over recent years there has been an increase in the number of ex situ conservation programmes involving both in vivo and in vitro preservation and the establishment of germplasm banks (Silva et al., 2012). The latter provides a means of connecting in situ and ex situ conservation programmes (Andrabi and Maxwell, 2007). However it will be difficult to optimize ovarian cryopreservation methods for rare or wild animals which may have highly specialized reproductive adaptations and/or for which only a limited amount of tissue can be safely harvested and cryopreserved. For this group ovarian cryopreservation protocols that have been developed for closely related domestic animals have been adapted and applied to preserve the germplasm of their endangered counterparts (Leibo and Songsasen, 2002). The avoidance of the impact of seasonality on mature oocyte quality and the lack of need for fresh or cryopreserved sperm for IVF at the time of oocyte harvest is a further significant practical advantage of ovarian tissue banking for animals species compared to oocyte or even embryo banking. For occasions where serious damage occurs that results in the unexpected slaughter of a valuable or particularly rare animal (e.g. after limb fracture) multiple ovarian cortical tissue fragments and/or whole ovary(s) can be harvested for storage. Thus cryopreservation strategies developed for, for example, cattle, sheep, goats, horses or pigs, can be used as models for tissue preservation in non-domestic ungulates, while domestic cats can provide valuable models for tissue preservation in wild felids (Luvoni, 2006), dogs for rare canids, and capuchin monkeys for new world primates etc (Comizzoli and Wildt, 2012). Ovarian tissue banking may therefore prove to be a practical and effective tool for the conservation of rare species.

\section{Fertility restoration following ovarian tissue cryopreservation}

A significant and outstanding challenge that needs to be addressed in parallel with the development and optimization of protocols for the banking and longterm storage of the germplasm for humans and domestic animals or wild species, is how best to use the stored tissue to restore fertility and/or generate offspring. Regardless of the origin of the stored ovarian tissue, our ability to realize its potential and produce viable offspring is rigidly linked to our depth of understanding of the reproductive characteristics of the species involved. Fertility restoration and live birth has been achieved in sheep and women where, in both cases, it is possible to autotransplant cryopreserved tissues. The issue of how to realize the potential of preserved ovarian tissues in wild animals or endangered species is far more challenging as autografting may not be feasible. Evidence from a number of species indicate that xenografting of cryopreserved ovarian tissue into mice with severe combined immunodeficiency may provide a temporary solution to this problem. Indeed, xenografting has been shown to support the activation of primordial follicle growth and antral follicle production in cryopreserved ovarian tissues from a range of rodent and domestic species including mouse (Snow et al., 2002), cat (Bosch et al., 2004), and cow as well as a variety of wild animals including tammar wallaby (Mattiske et al., 2002), common wombat (Cleary et al., 2003), African elephant, (Gunasena et al., 1998) and lion (Wiedemann et al., 2012). The combined approach of ovarian tissue banking followed by xenografting may in the future be used in conjunction with follicle culture technologies to produce full sized, MII oocytes for in vitro fertilisation and embryo transfer into a suitable recipient animal.

Multiphase culture strategies are being developed to support the complete in vitro growth and maturation (IVGM) of oocytes from the primordial follicle stage to maturity in the laboratory (Picton et al., 2008). This goal is very ambitious but never-the-less significant advances have been made in our ability to support the IVGM of oocytes in mice (Eppig and O’Brien 1996), sheep (Newton et al., 1999; Picton et al., 2003) cow, (McLaughlin and Telfer, 2010), non- 
human primates, (Xu et al., 2011) and humans (McLaughlin et al., 2018). To date the production of healthy, live offspring from primordial follicles has only been achieved in mice (Eppig and O'Brien, 1996; Hikabe et al., 2016; Hayashi et al., 2017). It is important to note that on the basis of the published literature it is highly likely that the culture timelines, nutrient requirements needed to support follicle and oocyte growth in vitro, the subsequent fertile capacity of the in vitro derived oocytes and, ultimately, the efficiency of IVGM strategies for cryobanked tissues will be species specific. Furthermore, it is likely that no single IVGM strategy will fit all species and IVGM strategies for rare or wild species will likely have to be used in conjunction with xenografting in order to realize the fertile potential of the stored germplasm.

\section{Conclusion}

In conclusion although many questions remain to be answered, considerable recent progress in cryobiology, reproductive science, and IVGM technology have led to therapeutic advances in clinical ART that have significantly improved our ability to cryopreserve female fertility by banking primordial oocytes in situ within ovarian tissues or by the vitrification of MII oocytes. The stage is now set to translate these clinical advances for animal conservation and to use them to develop comprehensive strategies that will not only safeguard the future genetic diversity of commercially important domestic species but will also facilitate germplasm preservation for animals at risk of extinction

\section{References}

Almodin CG, Minguetti-Camara VC, Meister H, Ferreira JO, Franco RL, Cavalcante AA, Radaelli MR, Bahls AS, Moron AF, Murta CG. 2004. Recovery of fertility after grafting of cryopreserved germinative tissue in female rabbitsfollowing radiotherapy. Hum Reprod, 19:1287-1293.

Andrabi SM, Maxwell WM. 2007. A review on reproductive biotechnologies for conservation of endangered mammalian species. Anim Reprod Sci, 99:223-243.

Baird DT, Webb R, Campbell BK, Harkness LM, Gosden RG. 1999. Long-term ovarian function in sheep after ovariectomy and transplantation of autografts stored at -196 C. Endocrinology, 140:462-471.

Baudot A, Courbiere B, Odagescu V, Salle B, Mazoyer C, Massardier J, Lornage J. 2007. Towards whole sheep ovary cryopreservation. Cryobiology, 55:236-248.

Bordes A, Lornage J, Demirci B, Franck M, Courbiere B, Guerin JF, Salle B. 2005. Normal gestations and live births after ortho-topic autograft of vitrified-warmed hemi-ovaries into ewes. Hum Reprod, 20:2745-2748.

Bosch P, Hernandez-Fonseca HJ, Miller DM, Wininger JD, Massey JB, Lamb SV, Brackett BG. 2004. Development of antral follicles in cryopreserved cat ovarian tissue transplanted to immunodeficient mice. Theriogenology, 61:581-594.

Boutelle S, LenahanK, Krisher R, Bauman KL, Asa CS, Silber S. 2011. Vitrification ofoocytes from endangered Mexican gray wolves (Canis lupus baileyi). Theriogenology, 75:647-654.

Campbell BK, Hernandez-Medrano J, Onions V, Pincott-Allen C, Aljaser F, Fisher J, McNeilly AS, Webb R, Picton HM. 2014. Restoration of ovarian function and natural fertility following the cryopreservation and autotransplantation of whole adult sheep ovaries. Hum Reprod, 29:1749-1763.

Candy CJ, Wood MJ, Whittingham DG. 1995. Follicular development in cryopreserved marmoset ovarian tissue after transplantation. Hum Reprod, 10:2334-2338.

Carvalho AA, Faustino LR, Silva CM, Castro SV, Lopes CA, Santos RR, Báo SN, Figueiredo JR, Rodrigues AP. 2013 Novel wide-capacity method for vitrification of caprine ovaries: ovarian tissue cryosystem (OTC). Anim Reprod Sci, 138:220-227.

Chambers EL, Gosden RG, Yap C, Picton HM. 2010. In situ identification of follicles in ovarian cortex as a tool for quantifying follicle density, viability and developmental potential in strategies to preserve female fertility. Hum Reprod, 25:2559-2568.

Cleary M, Paris MCJ, Shaw J, Jenkin G, Trounson A. 2003. Effect of ovariectomy and graft position on cryopreserved commonwombat (Vombatus ursinus) ovarian tissue following xenografting to nude mice. Reprod Fertil Dev, 15:333-334.

Cobo A, García-Velasco JA. 2016. Why all women should freeze their eggs. Curr Opin Obstet Gynecol, 28:206-210.

Comizzzoli P, Wildt DE, Pukazhenti BS. 2008. Impact of anisosmotic conditions on structural integrity of cumulus-oocyte complexes at the germinal vesicle stage in the domestic cat. Mol Reprod Dev, 75:345-354.

Comizzoli P, Crosier AE, Songsasen N, Gunther MS, Howard JG, Wildt DE. 2009. Advances in reproductive science for wild carnivore conservation. Reprod Domest Anim, 44(suppl. 2):47-52.

Comizzoli P, Songsasen N, Wildt DE. 2010. Protecting and extending fertility for females of wild and endangered mammals. Cancer Treat Res, 156:87100 .

Comizzoli P, Songsasen N, Hagedorn M, Wildt DE. 2012. Comparitive cryobiological traits and requirements for gametes and gonadal tissues collected from wildlife species. Theriogenology, 78:1666-1681.

Comizzoli P, Wildt DE. 2012. On the horizon for fertility preservation in domestic and wild carnivores. Reprod Domest Anim, 47(suppl. 6):261-285.

Comizzoli P. 2017. Biobanking and fertility preservation for rare and endangered species. Anim Reprod, 14:30-33.

Czarny NA, Roger JC. 2010. Vitrification as a method forgenome resource banking from the endangered Tasmanian devil (Sarcophilus harrisii). Cryobiology, 60:322-325

Demeestere I, Simon P, Dedeken L, Moffa F, Tsépélidis S, Brachet C, Delbaere A, Devreker F, 
Ferster A. 2015. Live birth after autograft of ovarian tissue cryopreserved during childhood. Hum Reprod, 30:2107-2109.

Devi L, Goel S. 2016. Fertility preservation through gonadal cryopreservation. Reprod Mol Biol, 15:235251.

Dolmans MM, Masciangelo R. 2018. Risk of transplanting malignant cells in cryopreserved ovarian tissue. Minerva Ginecol, 70:436-443.

Ehmcke J, Schlatt S. 2008. Animal models for fertility preservation in the male. Reproduction, 136:717-723

Eppig JJ, O'Brien MJ. 1996. Development in vitro of mouse oocytes from primordial follicles. Biol Reprod, 54:197-207

Fernandez-Gonzalez L, Jewgenow K. 2017. Cryopreservation of feline oocytes by vitrification using commercial kits and slush nitrogen technique. Reprod Domest Anim, 52(suppl. 2):230-234

Gandolfi F, Paffoni A, Papasso Brambilla E, Bonetti S, Brevini TA, Ragni G. 2006. Efficiency of equilibrium cooling and vitrification procedures for the cryopreservation of ovarian tissue: comparative analysis between human and animal models. Fertil Steril, 85(suppl. 1):1150-1156

Gellert SE, Pors SE, Kristensen SG, Bay-Bjørn AM, Ernst E2, Yding Andersen C. 2018. Transplantation of frozen-thawed ovarian tissue: an update on worldwide activity published in peer-reviewed papers and on the Danish cohort. J Assist Reprod Genet, 35:561-570.

Glujovsky D, Riestra B, Sueldo C, Fiszbajn G, Repping S, Nodar F, Papier S, Ciapponi A. 2014. Vitrification versus slow freezing for women undergoing oocyte cryopreservation. Cochrane Database Syst Rev, (9):CD010047. doi:10.1002/14651858.CD010047.

Goldman RH, Racowsky C, Farland LV, Munné S, Ribustello L, Fox JH. 2017. Predicting the likelihood of live birth for elective oocyte cryopreservation: a counseling tool for physicians and patients. Hum Reprod, 32:853-859.

Gosden RG, Baird DT, Wade JC, Webb R. 1994. Restoration of fertility to oophorectomized sheep by ovarian autografts stored at -196 degrees C. Hum Reprod, 9:597-603.

Gunasena KT, Lakey JR, Villines PM, Bush M, Raath C, Critser ES, McGann LE, Critser JK. 1998 Antral follicles develop in xenografted cryopreserved African elephant (Loxodonta africana) ovarian tissue. Anim Reprod Sci, 53:265-275.

Harp R, Leibach J, Black J, Keldahl C, Karow A. 1994. Cryopreservation of murine ovarian tissue. Cryobiology, 31:336-343

Hayashi K, Hikabe O, Obata Y, Hirao Y. 2017. Reconstitution of mouse oogenesis in a dish from pluripotent stem cells. Nat Protoc, 12:1733-1744.

Hikabe O, Hamazaki N, Nagamatsu G, Obata Y, Hirao Y, Hamada N, Shimamoto S, Imamura T, Nakashima K, Saitou M, Hayashi K. 2016. Reconstitution in vitro of the entire cycle of the mouse female germ line. Nature, 539:299-303.

Howard JG, Wildt DE. 2009. Approaches and efficacy of artificial insemination in felids and mustelids. Theriogenology, 71:130-148.

Huang Y, Li D, Zhou Y, Zhou Q, Li R, Wang C, Huang Z, Hull V, Zhang H. 2012. Factors affecting the outcome of artificial insemination using cryopreserved spermatozoa in the giant panda (Ailuropoda melanoleuca). Zoo Biol, 31:561-173

Ishijima T, Kobayashi Y, Lee DS, Ueta YY, Matsui M, Lee JY, Miyahara K, Suzuki H. 2006. Cryopreservation of canine ovaries by vitrification. $J$ Reprod Dev, 52:293-299.

Jadoul P, Guilmain A, Squifflet J, Luyckx M, Votino R, Wyns C, Dolmans MM. 2017. Efficacy of ovarian tissue cryopreservation for fertility preservation: lessons learned from 545 cases. Hum Reprod, 32:1046-1054.

Kagawa N, Silber S, Kuwayama M. 2009. Successful vitrification of bovine and human ovarian tissue. Reprod Biomed Online, 18:568-577.

Kedem A, Yerushalmi GM, Brengauz M, Raanani H, Orvieto R, Hourvitz A, Meirow D. 2018. Outcome of immature oocytes collection of 119 cancer patients during ovarian tissue harvesting for fertility preservation. J Assist Reprod Genet, 35:851-856.

Kim SS, Radford J, Harris M, Varley J, Rutherford AJ, Lieberman B, Shalet S, Gosden R. 2001. Ovarian tissue harvested from lymphoma patients to preserve fertility may be safe for autotransplantation. Hum Reprod, 16:2056-2060

Kim SS, Kang HG, Kim NH, Lee HC, Lee HH. 2005. Assessment of the integrity of human oocytes retrieved from cryopreserved ovarian tissue after xenotransplantation. Hum Reprod, 20:2502-2508.

Leibo SP, Songsasen N. 2002. Cryopreservation of gametes and embryos of non-domestic species. Theriogenology, 57:303-326.

Luvoni GC. 2006. Gamete cryopreservation in the domestic cat. Theriogenology, 66:101-111.

Madboly MM, Abdel-Aal ES, Elsayed EH. 2017. Impact of cryopreservation method on dromedary camel ovary structure, viability, and development of antral follicular oocytes. Anim Reprod Sci, 184:120-131.

Martinez-Madrid B, Dolmans MM, Van Langendonckt A, Defrère S, Donnez J. 2004. Freezethawing intact human ovary with its vascular pedicle with a passive cooling device. Fertil Steril, 82:13901394.

Matthews SJ, Picton HM, Ernst E, Andersen CY. 2018. Successful pregnancy in a woman previously suffering from $\beta$-thalassaemia following transplantation of ovarian tissue cryopreserved before puberty. Minerva Ginecol, 70:432-435.

Mattiske D, Shaw G. Shaw J.M. 2002. Infuence of donor age on development of gonadal tissue from pouch young of the tammar wallaby, Macropus eugenii, after cryopreservation and xenografting into mice. Reproduction, 123:143-153

Migishima F, Suzuki-Migishima R, Song SY, Kuramochi T, Azuma S, Nishijima M, Yokoyama M. 2003. Successful cryopreservation of mouse ovaries by vitrification. Biol Reprod, 68:881-887.

Mullen SF, Agca Y, Broermann DC, Jenkins CL, Johnson CA, Critser JK. 2004. The effect of osmotic 
stress on the metaphase II spindle of human oocytes, and the relevance to cryopreservation. Hum Reprod, 19:1148-1154.

Newton H, Aubard Y, Rutherford A, Sharma V, Gosden R. 1996. Low temperature storage and grafting of human ovarian tissue. Hum Reprod, 11:1487-1491.

Newton H, Fisher J, Arnold JR, Pegg DE, Faddy MJ, Gosden RG. 1998. Permeation of human ovarian tissue with cryoprotective agents in preparation for cryopreservation. Hum Reprod, 13:376-380.

Newton H, Picton HM, Gosden RG. 1999. In vitro growth of preantral follicles isolated from frozen/thawed ovine tissue. J Reprod Fertil, 115:141-150.

Oktay K, Newton H, Mullan J, Gosden RG. 1998. Development of human primordial follicles to antral stages in SCID/hpg mice stimulated with follicle stimulating hormone. Hum Reprod, 13:1133-1138.

Oktay K, Cil AP, Bang H. 2006. Efficiency of oocyte cryopreservation: a meta-analysis. Fertil Steril, 86:7080.

Oktay K, Bedoschi G, Berkowitz K, Bronson R, Kashani B, McGovern P, Pal L, Quinn G, Rubin K. 2016. Fertility preservation in women with turner syndrome: a comprehensive review and practical guidelines. J Pediatr Adolesc Gynecol, 29:409-416.

Oktay K, Harvey BE, Partridge AH, Quinn GP, Reinecke J, Taylor HS, Wallace WH, Wang ET, Loren AW. 2018. Fertility preservation in patients with cancer: ASCO clinical practice guideline update. J Clin Oncol, 36:1994-2001.

Onions VJ, Webb R, McNeilly AS, Campbell BK. 2009. Ovarian endocrine profile and long-term vascular patency following heterotopic autotransplantation of cryopreserved whole ovine ovaries. Hum Reprod, 24:2845-2855.

Onions VJ, Webb R, Pincott-Allen C, Picton HM, Campbell BK. 2013. The effects of whole ovarian perfusion and cryopreservation on endothelial cellrelated gene expression in the ovarian medulla and pedicle. Mol Hum Reprod, 19:205-215.

Ortiz-Escribano N, Bogado Pascottini O, Woelders $H$, Vandenberghe $L$, De Schauwer $C$, Govaere J, Van den Abbeel E, Vullers T, Ververs C, Roels K, Van De Velde M, Van Soom A, Smits K. 2018. An improved vitrification protocol for equine immature oocytes, resulting in a first live foal. Equine Vet $J$, 50:391-397.

Pacheco F, Oktay K. 2017. Current success and efficiency of autologous ovarian transplantation: a metaanalysis. Reprod Sci, 24:1111-1120.

Parrott DMV. 1960. The fertility of mice with orthotopic ovarian grafts derived from frozen tissue. $J$ Reprod Fertil, 1:230-241.

Paulson RJ, Comizzoli P. 2018. Addressing challenges in developing and implementing successful in vitro fertilization in endangered species: an opportunity for humanity to "give back". Fertil Steril, 109:418-419.

Pickering SJ, Johnson MH. 1987. The influence of cooling on the organization of the meiotic spindle of the mouse oocyte. Hum Reprod, 2:207-216.

Pickering SJ, Braude PR, Johnson MH, Cant A, Currie J. 1990. Transient cooling to room temperature can cause irreversible disruption of the meiotic spindle in the human oocyte. Fertil Steril, 54:102-108.

Picton HM, Kim S, Gosden RG. 2000. Cryopreservation of gonadal tissue and cells. $\mathrm{Br} \mathrm{Med}$ Bull, 56:603-615.

Picton HM. 2001. Activation of follicle development: the primordial follicle. Theriogenology, 55:1193-1210.

Picton HM, Danfour MA, Harris SE, Chambers EL, Huntriss J. 2003. Growth and maturation of oocytes in vitro. Reprod Suppl, 61:445-462.

Picton HM, Harris SE, Muruvi W, Chambers EL. 2008. The in vitro growth and maturation of follicles. Reproduction, 136:703-715.

Picton H, Chambers E. 2009. Egg freezing: the reality and practicality. In: Bewley S, Ledger W, Nikolaou D (Ed.). Reproductive Ageing. London: Cambridge University Press. pp. 211-226.

Picton HM, Wyns C, Anderson RA, Goossens E, Jahnukainen K, Kliesch S, Mitchell RT, Pennings G, Rives N, Tournaye H, Van Pelt AMM, EichenlaubRitter U, Vanden Abbeel E, Schlatt S. 2015. A European perspective on testicular tissue cryopreservation for fertility preservation in prepubertal and adolescent boys. Hum Reprod, 11:2463-2475.

Rahimi G, Isachenko E, Isachenko V, Sauer H, Wartenberg M, Tawadros S, Hescheler J, Mallmann P, Nawroth F. 2004. Comparison of necrosis in human ovariantissue after conventional slow freezing or vitrification and transplantation in ovariectomized SCID mice. Reprod Biomed Online, 9:187-193

Rienzi L, Gracia C, Maggiulli R, LaBarbera AR, Kaser DJ, Ubaldi FM, Vanderpoel S, Racowsky C. 2017. Oocyte, embryo and blastocyst cryopreservation in ART: systematic review and meta-analysis comparing slow-freezing versus vitrification to produce evidence for the development of global guidance. Hum Reprod Update, 23:139-155.

Santana LN, Van den Hurk R, Oskam IC, Brito AB, Brito DC, Domingues SF, Santos RR. 2012. Vitrification of ovarian tissue from primates and domestic ruminants: an overview. Biopreserv Biobank, 10:288-294.

Santos RR, Tharasanit T, Van Haeften T, Figueiredo JR, Silva JR, Van den Hurk R. 2007. Vitrification of goat preantral follicles enclosed in ovarian tissue by using conventional and solid-surface vitrification methods. Cell Tissue Res, 327:167-176.

Saragusty J, Arav A. 2011. Current progress in oocyte and embryo cryopreservation by slow freezing and vitrification. Reproduction, 141:1-19. doi: 10.1530/REP-10-0236.

Silva RC, Costa GM, Lacerda SM, Batlouni SR, Soares JM, Avelar GF, Böttger KB, Silva SF Jr, Nogueira MS, Andrade LM, França LR. 2012. Germ cell transplantation in felids: a potential approach to preserving endangered species. J Androl, 33:264-276.

Snow M, Cox SL, Jenkin G, Trounson A, Shaw J. 2002. Generation of live young from xenografted mouse ovaries. Science, 297:2227.

Songsasen N, Ratterree MS, VandeVoort CA, Pegg DE, Leibo SP. 2002. Permeability characteristics and osmotic sensitivity of rhesus monkey (Macaca mulatta) 
oocytes. Hum Reprod, 17:1875-1884.

Suzuki N, Yoshioka N, Takae S, Sugishita Y, Tamura M, Hashimoto S, Morimoto Y, Kawamura K. 2015. Successful fertility preservation following ovarian tissue vitrification in patients with primary ovarian insufficiency. Hum Reprod, 30:608-615.

Taberlet P, Valentini A, Rezaei HR, Naderi S, Pompanon F, Negrini R, Ajmone-Marsan P. 2008. Are cattle, sheep, and goats endangered species? $\mathrm{Mol}$ Ecol, 17:275-284.

Tokieda Y, Ishiwata I, Segino M, Ishikawa H, Sato K. 2002. Establishment of a novel method for cryopreservation and thawing of the mouse ovary. Hum Cell, 15:230-237.

Wang X, Chen H, Yin H, Kim SS, Lin Tan S, Gosden RG. 2002. Fertility after intact ovary transplantation. Nature, 415:385.

Whittingham DG, Leibo SP, Mazur P. 1972. Survival of mouse embryos frozen to -196 degrees and -269 degrees C. Science, 178:411-414.

Wiedemann C, Hribal R, Ringleb J, Bertelsen MF, Rasmusen K, Andersen CY, Kristensen SG,
Jewgenow K. 2012. Preservation of primordial follicles from lions by slow freezing and xenotransplantation of ovarian cortex into an immunodeficient mouse. Reprod Domest Anim, 47(suppl. 6):300-304.

Wildt DE, Comizzoli P, Pukazhenthi B, Songsasen N. 2010. Lessons from biodiversity- the value of nontraditional species to advance reproductive science, conservation, and human health. Mol Reprod Dev, 77:397-409.

Woods EJ, Benson JD, Agea Y, Critser JK. 2004. Fundamental cryobiology of reproductive cells and tissues. Cryobiology, 48:146-156.

Xu M, Fazleabas AT, Shikanov A, Jackson E, Barrett SL, Hirshfeld-Cytron J, Kiesewetter SE, Shea LD, Woodruff TK. 2011. In vitro oocyte maturation and preantral follicle culture from the lutealphase baboon ovary produce mature oocytes. Biol Reprod, 84:689-697.

Zenzes MT, Bielecki R, Casper RF, Leibo SP. 2001. Effects of chilling to 0 degrees $\mathrm{C}$ on the morphology of meiotic spindles in human metaphase II oocytes. Fertil Steril, 75:769-777. 